\title{
PERSPECTIVAS Y PERCEPCIONES DE LIBERTAD EN LAS AMÉRICAS
}

\author{
Perspectives and perceptions of freedom in the Americas
}

Gilda Pacheco*

\section{RESUMEN}

El siguiente artículo analiza las perspectivas y percepciones del concepto de libertad esbozadas en canciones populares provenientes de las tres Américas y compuestas en la década de los años 80 . Desde un enfoque comparativo literario, en donde las canciones se visualizan como poemas, y complementado por teorías culturales, diferencias y similitudes de esta temática son expuestas y estudiadas para lograr una mejor comprensión de diversas culturas.

Palabras clave: tema de libertad, canciones populares, estudios culturales, literatura comparada, cultura popular, la década de los 80 .

\begin{abstract}
The following article analyzes the perspectives and perceptions of freedom present in popular songs written in the $80 \mathrm{~s}$ in different countries of the American Continent. From a literary comparative approach, where songs are seen as poems, reinforced by cultural theories, differences and similarities of the topic are exposed and studied in order to obtain a better understanding of different cultures.

Key Words: the topic of freedom, popular culture, cultural studies, comparative literature, popular songs, the decade of the $80 \mathrm{~s}$.
\end{abstract}

Universidad de Costa Rica, Directora de la Escuela deLenguas Modernas. Costa Rica

Correo electrónico: gilda.pacheco@ucr.ac.cr

Recepción: 23/4/14. Aceptación: 24/3/15. 
Podría decirse que lo lógico para iniciar un artículo con este título sería el tratar de definir un término tan importante y transcendental, tan deseado por muchos, tan idealizado por otros y tan utilizado en el lenguaje, ya sea literario o popular, es decir, iniciar por definir el concepto de libertad. Sin embargo, tal definición constituye un reto y en realidad es su percepción o percepciones lo que expone diferencias, al igual que similitudes, sociales, políticas, colectivas e individuales. La libertad es entonces un tema propicio para un análisis comparativo y a la vez un tema recurrente en la literatura universal.

La libertad puede considerarse como la capacidad del ser humano para poder ejercer su voluntad, o el derecho que tiene todo individuo de determinación. La libertad es visualizada como motor de acción para combatir la imposición o marginalización, e incluso el ideal que justifica un acto de rebelión o de revolución. $\mathrm{Si}$ buscamos sinónimos, "autonomía" sería una excelente opción; si buscamos antónimos, sin duda éste sería "opresión". Según algunos filósofos franceses, la libertad es inherente al ser humano, pues éste nace libre, pero la sociedad o las circunstancias lo encadenan o lo corrompen. La libertad está entonces en la interioridad del individuo, aunque también debería estar presente en la sociedad; en suma, la libertad es tema idóneo para un análisis comparativo de corte tanto literario como cultural.

Hace ya bastante tiempo la literatura comparada dejó de ser el exclusivo análisis de textos literarios y realizando otro tipo de comparaciones logró exponer su carácter interdisciplinario. Mi ponencia tiende en esta dirección, pues presenta la convergencia de la literatura comparada y los estudios culturales, es decir, estudios de articulación social que buscan borrar fronteras disciplinarias, lingüísticas, discursivas, geográficas o sociales, meta también compartida por la literatura comparada. Algunos críticos comparatistas, como Roland Greene ven en el campo de los Estudios Culturales una fuerza renovadora de la Literatura Comparada. Otros, como Haun Saussy, visualizan una competencia entre estos dos campos y otros, como Jonathan Culler, señalan el aspecto interdisciplinario teórico como punto de enlace de ambos campos. Puesto que los estudios culturales abarcan muchas áreas, para mi ponencia he seleccionado el ámbito de la cultura popular, es decir, el conjunto de ideas, actitudes, percepciones, imágenes o artefactos de la gente que tipifican a una sociedad; en donde las canciones son ejemplos innegables de cultura popular, ya que sus líricas revelan preocupaciones y deseos tanto universales como personales, según el compositor o compositora, su contexto social, su país natal o de residencia y su época.

En este artículo, las canciones populares serán analizadas como textos poéticos en cuanto a imágenes, lenguaje literario o tono se refiere. Para este trabajo, he seleccionado tres canciones de tres países representantes, geográficamente hablando, de las tres Américas que forman nuestro continente: Argentina en América del Sur, Costa Rica en América Central y Estados Unidos en la América del Norte. En otras palabras, analizaré canciones de las tres Américas, escritas en inglés o en español que fueron compuestas en la década de los años 80. Así, he limitado espacios geográficos y una época, y con estos dos parámetros exploraré el tema de libertad, mediante un enfoque de comparación literaria complementado por premisas teóricas del campo de los estudios culturales.

En Argentina, la canción seleccionada es "Inconsciente colectivo" de Charly García. Antes de iniciar su análisis repasemos brevemente el contexto social del país natal de su compositor. La Argentina de los años 80 presenta tensión, conflictos e inestabilidad. Cuatro presidentes: Videla, Viola, Galtieri y Bignone están al frente del país en los primeros cuatro años de dicha década. La pérdida de las islas Malvinas en el 1982, cuando Inglaterra gana la guerra y toma posesión de estos territorios, deja una cicatriz profunda en el pueblo argentino. En 1983 Raúl Alfonsín toma el poder y se habla entonces de un "regreso a la democracia". Pero a mitad de esta década, Alfonsín inicia los famosos juicios contra represores militares, que provocan una revuelta en contra del gobierno, 
terminando con su período presidencial en 1989. En el campo económico, grandes gastos del gobierno, grandes aumentos de salarios, entre otros factores, conducen a una crónica inflación y por ende a una enorme deuda externa que causa la crisis económica de final de década. La canción de Charly García es compuesta a inicios de los 80 y refleja en forma elocuente el sentir popular. Y siguiendo el orden cronológico de creación de las composiciones musicales escogidas, continuamos nuestro recorrido ahora hacia Centroamérica.

En Costa Rica, la canción seleccionada es "Las últimas y (más viejas) noticias" letra compuesta por Alexander Loynaz y Bernal Villegas, música también compuesta por Villegas, ambos miembros del grupo Shénuk. La Costa Rica de los años 80 presenta inestabilidad y tensión al inicio de la década, pero equilibrio $\mathrm{y}$ balance al final de la misma. Tiene tres presidentes que gobernarían en condiciones diferentes. Rodrigo Carazo, quien funda "La Universidad de la Paz", finaliza su periodo en 1982 y enfrenta la difícil recesión económica de los precios del alza del petróleo, mientras que los precios del café, principal producto nacional de aquel tiempo, caían estrepitosamente. Luis Alberto Monge, presidente hasta 1986, desarrolla programas de austeridad, reduce la inflación y el desempleo e instala una política de neutralidad con la región centroamericana. Finalmente, es Oscar Arias quien termina la década con una economía más establece y es galardonado con el premio Nobel de la Paz en 1987, por su esfuerzo en tratar de ayudar a detener la guerra en los países centroamericanos. Esta preocupación por Centroamérica se percibe en la letra de la canción del grupo Shénuk la cual fue compuesta a mediados de la década de los 80 cuando El Salvador y otros países hermanos vivían situaciones muy difíciles por las guerrillas y la opresión. Continuando el recorrido cronológico de las composiciones musicales, nos dirigimos entonces a la América del Norte.

EnEstados Unidos, la canción seleccionada es "Freedom Now" de Tracy Chapman. En los años 80, un solo presidente está en el poder: Ronald Reagan, republicano que ocupará la Casa
Blanca de 1981 a 1989. La llamada "Guerra Fría" entre los Estados Unidos y la antigua Unión Soviética, por la temida amenaza nuclear, marca el inicio de esta década. El terrorismo internacional aumenta y se provocan revueltas tanto dentro como fuera del país. Vemos como el presidente mismo es víctima de un atentado de asesinato y como los Estados Unidos entra en conflicto con Libia y Panamá. En cuanto al aspecto económico, Reagan establece varias medidas de libre comercio que crean la base de la economía neoliberal estadounidense de los siguientes años. Para algunos estas medidas conducen a crear estabilidad, mientras que para otros las mismas contribuyen a una posterior crisis económica. La canción de Tracy Chapman, compuesta al final de la década, ejemplifica el sentir de protesta en la búsqueda de una mejora social.

Es el momento entonces de iniciar una comparación literaria, de textos tradicionalmente no literarios, productos de cultura popular. Aunque si lo pensamos mejor, la música y la poesía siempre han estado de la mano, y la única diferencia entre un poema y una canción, cuando ésta última presenta un mensaje, es que la canción tiene música y en ese sentido, escucharla resulta doblemente placentero.

Charly García, argentino, es considerado uno de los más importantes compositores y cantantes de rock. Pianista, productor, guitarrista, García comienza su carrera a fines de los años 60. Aunque se le llama el Rey del Rock Argentino, su reputación es internacional y su influencia es clara, sobre todo en los músicos de rock latinoamericanos. En 1982, García comienza su carrera como solista e incluye la canción "Inconsciente colectivo" en su álbum titulado Yendo de la cama al living. García, utilizando el término del psiquiatra y psicólogo suizo Carl Jung como título de su canción, presenta un mensaje de libertad para sus compatriotas, buscando o anticipando una nueva democracia para su país. Así, en sus líricas, García usa el concepto de inconsciente colectivo, de esa herencia humana e innata que aparece como forma estructural en todos los individuos, 
inconsciente que nos unifica al aspirar y esperar lo mismo, en este caso, la libertad.

La canción "Inconsciente colectivo" está compuesta por veintitrés líneas. Inicia con un listado de imágenes sensoriales que ayudan al oyente a ser parte del mundo del yo lírico que dice: "Nace una flor, todos los días sale el sol/ de vez en cuando escuchas aquella voz/Como de pan, gustosa de cantar en los aleros de mi mente con las chicharras" (1-3). Así, imágenes visuales como la flor que a la vez evoca un aroma, y el sol que a la vez calienta la piel, se confunden con imágenes sonoras como la voz que canta en la mente del yo lírico junto con el canto de las chicharras. Además, la presencia de diferentes acciones como nacer, salir, escuchar y cantar ayuda a brindar dinamismo y vitalidad a estas líricas. Pero al lado del paradisíaco ambiente inicial, aparece la imagen de un transformador que consume al individuo y lo oprime: "te tira hacia atrás, te pide más y más" (6), dice la canción. La solución es "la libertad, [porque] siempre la llevarás dentro del corazón" (8-9). Y así, según la canción de Charly García aunque nos opriman, la libertad siempre está en nuestra interioridad, como parte de la esencia humana, como una forma de enfrentar lo malo, como inspiración para volver a cantar.

Se observa como la canción comienza con imágenes concretas de la naturaleza y luego presenta conceptos abstractos, como la corrupción, el olvido y la misma libertad. Después vemos la imagen de los sueños que se articula con la imagen de "los aleros de la mente", ambas imágenes mencionadas por el compositor, siguiendo así la teoría de Jung, en donde el yo lírico nos dice: "Ayer soñé con los hambrientos, los locos, los que se fueron, los que están en prisión" (17-18). Tenemos entonces hambrientos, dementes, desertores, o prisioneros, en fin grupos de individuos marginados por la sociedad. Sin embargo, el autor exhibe al final optimismo al decir que hoy es diferente, pues "hoy desperté cantando esta canción que ya fue escrita hace tiempo atrás" (20-21). Con binarismos como "el hoy y el ayer", "el soñar y el dormir", el yo lírico concluye la canción, en tono entusiasta, al decir: "Es necesario cantar de nuevo, una vez más” (22-23). Y ese canto es un llamado de libertad. Pero la temática de libertad en la composición de canciones, no fue exclusiva en Suramérica, también inspiró a otros músicos de rock en América Central.

Shénuk fue un grupo de rock progresivo en Costa Rica que se mantuvo activo de 1982 a 1986. La agrupación se orientaba hacia un tipo de rock sinfónico, y a la vez rock urbano, para mantener un sonido original. Entre sus temas destacaron el pacifismo y la preocupación social y existencial. Para algunos Shénuk apareció adelantado para su época.. Sin embargo, el grupo compuso canciones que tienen un lugar muy especial en la historia del rock costarricense y una de ellas es "Las últimas (y más viejas) noticias" grabada en 1985. Entre los integrantes del grupo destaca el compositor, guitarrita y cantante costarricense Bernal Villegas quien es la persona que compone la música y coautor de la letra de esta canción. Después de la disolución de Shénuk, este cantante y compositor formó parte de otros grupos musicales y actualmente tiene su propia banda llamada Villegas.

"Las últimas (y más viejas) noticias" está dividida en cuatro estrofas. El yo lírico es en realidad un lector de periódico quien está perturbado al ir leyendo las noticias. La canción comienza diciendo: "Con ganas de hacer tanto/ por resolver/Noticias en los diarios/son las que me tienen sin sueño" (1-4). En la segunda estrofa se enfatiza el proceso de lectura al ir pasando las páginas del diario y se destaca la angustia del lector ante problemas sociales como la pobreza y la guerra. Así, la última línea de la segunda estrofa señala que no hay "ni paz, ni pan, ni libertad" (11). En la tercera estrofa, el yo lírico establece una comparación al expresar: "Tal vez sos muy pequeño al comparar/pero hay muchos sin sueño..." (15-16) y así se refiere al otro o a los otros que quieren formar "un río de fuerte caudal" para gritar bien alto exigiendo libertad. Esta tercera estrofa finaliza con la palabra "libertad", enfatizando no solo la última sílaba de la palabra sino la propuesta de unión y solidaridad humana que pueda lograr metas importantes para mejorar la sociedad. La última y cuarta estrofa de la canción es prácticamente una repetición de las últimas líneas de la tercera estrofa y sus líricas son: "y gritemos bien 
alto/Queremos la paz/Queremos desarmes/y la libertad aaa...aaa...aaa" (22-25).

En síntesis, la canción del grupo Shénuk aunque presenta imágenes concretas como las páginas del diario, exhibe más imágenes abstractas como el insomnio, el sufrimiento, el hambre, y la libertad. La imagen del río es peculiar ya que toma la fuerza del caudal natural, pero en realidad el río es una metáfora que simboliza solidaridad social. En imágenes sensoriales destacan las visuales, ya que es un lector quien, página por página va leyendo y descubrimiento los problemas sociales que presenta el diario. Pero no es un lector pasivo, sino como Cortázar espera del lector de Rayuela, se trata de un lector activo que no puede ser indiferente al sufrimiento de la gente, que se desvela y así se une al grito de libertad, imagen recurrente en la canción y enfatizada en su última línea con la repetición de la vocal "a" en la sílaba final. El tono de la pieza de Shénuk "Las últimas (y más viejas) noticias" es realista, pues expone problemas reales y actuales y también, a la vez, presenta un tono demandante, ya que estas líricas exigen cambios para ayudar a otros, particularmente a los que sufren en otros países centroamericanos, pero que en realidad estos problemas aquejan a toda la humanidad. Así, las últimas noticias son tristemente también las más viejas, los mismos problemas sociales siguen presentes. Y esta misma denuncia de falta de libertad es también expuesta por compositores norteamericanos.

Tracy Chapman, estadounidense, famosa compositora y cantautora, es considerada como una de las figuras artísticas que reivindica la popularidad del cantautor. En sus composiciones se destaca la música de protesta de temática político-social. Ganadora de varios premios Grammy, Chapman graba en 1989 su segundo álbum llamado Crossroads en donde aparece "Freedom Now", la canción que vamos a analizar. Compuesta de 47 líneas, agrupadas en 11 estrofas, "Freedom Now" ha sido considerada por algunos como una pieza dedicada a Nelson Mandela. Sin embargo, el llamado de libertad que formula Chapman en sus líricas, es universal y el tema de protesta que allí se presenta, va muy acorde con los acontecimientos de la época que vivió la sociedad norteamericana.

La canción comienza con una negación de libertad física que conducirá a la falta de libertad espiritual y mental, pues, como dice, el yo lírico: "They throw him in jail" (lo encerraron en la cárcel)/ "And they kept him there" (y lo mantuvieron allí)/ "Hoping soon he'd die" (esperando que se muriera pronto)/ "That his body and spirit would waste away" (que su cuerpo y espíritu se consumieran)/ "And soon after that his mind" (y después de esto, su mente) (1-5). Vemos entonces una serie de transgresiones del estado físico al mental. La estrofa cuarta es una variación de la primera en donde también se espera que además de su cuerpo, espíritu y mente, también su memoria desaparezca para que la gente olvide que existió alguien que luchó por justicia y libertad. Sin embargo, aunque en la canción se presenta la confrontación de ellos contra él, Chapman hace un llamado de libertad para todos y todas, pues en la segunda estrofa afirma que "...every day is born a fool"/ (todos los días nace un tonto)/ "One who thinks that he can rule"/ (quien piensa que puede gobernar)/ "One who says tomorrow's mine" (Alguien que dice el mañana me pertenece) (6-8). Por lo tanto, falta de capacidad intelectual o enfermizas ansias de poder, características recurrentes en muchos gobernantes, provocan la opresión de los pueblos. La quinta estrofa es una variación de la segunda, ya que ahora no se trata de un tonto sino de un individuo que odia lo que no puede comprender, que piensa que el matar es la solución a los problemas y quien se considera un hombre libre. Vemos entonces, una forma de libertad dañina que ilustra Chapman con la imagen de este tirano libre de acción, que oprime y aniquila a los otros.

Sin embargo, aunque el tono es demandante y las escenas descritas son bastante negativas, al final de la canción de Chapman, el yo lírico cree en la esperanza de obtener una libertad positiva que beneficie a todos y a todas, pues nos dice que lo malo puede corregirse, que los injustamente encarcelados pueden ser liberados y para ser libres completamente se debe: "Free our bodies, free our minds, (liberar nuestros cuerpos, liberar nuestras mentes, 38) 
y añade un tercer elemento: "Free our hearts (liberar nuestros corazones, 39) Es decir, demanda el poder gozar de libertad total de acciones, de pensamientos y de sentimientos para obtener un bienestar no individual sino más bien social y así lograr: Freedom for everyone (libertad para todos)/And freedom now (Y libertad ahora, 40-41).

A diferencia de las otras dos canciones, las imágenes de Chapman son más concretas y definidas. La cantautora describe situaciones de opresión y evoca diferentes tipos de libertad. No obstante, las tres canciones se complementan, pues el deseo de libertad, parte del inconsciente que evoca Charly García, es, después de todo, colectivo, no individual y si una persona comienza por hacer consciencia de esto, podrá ayudar a los otros solidariamente, como lo expresa el grupo Shénuk en su canción, para que los mismos hechos no se repitan, para que las noticias de opresión de antes no sean las de la actualidad, para que se escriban diferentes canciones, no pidiendo, ni denunciando, ni reclamando la falta de libertad, sino más bien celebrando su existencia.

Al considerar algunas premisas del enfoque de los estudios culturales, en cuanto a cultura popular se refiere, surgen varias nociones importantes. Podríamos pensar en cómo las canciones populares nacen o cómo la gente las interpreta o qué efectos las mismas provocan en la sociedad. Se podría argumentar que nacen de los deseos, esperanzas o miedos de las personas. Cada "fan", ya sea de música rock o de música de protesta o de música en general, las interpretará según su edad, experiencia de vida y contexto social. Como hemos visto, las tres canciones analizadas nacen de la preocupación de no poseer o perder la libertad, pero no en un sentido personal sino colectivo, pues las tres muestran el interés por los demás.

Según las premisas teóricas sobre la cultura popular, la gente es vista como una fuente creadora de significado, pues como Wendy Griswold lo afirma, los receptores interpretan los objetos culturales para producir sus propios significados (83); aunque en este caso los compositores esperarían que siempre se rescate el mensaje social. Sin embargo, no debemos olvidar que las canciones son productos culturales masivos, producidas, como afirma Dominic Strinati, "por técnicas de producción industrial para lograr ganancias y van dirigidas al público, visualizado como consumidores en masa" (10, traducción propia). Se debe considerar que los músicos, compositores o cantantes aumentan su popularidad si cuentan con una mayor difusión para poder lograr una mayor recepción. Si bien es cierto que pertenecen a mercados culturales que responden a cambios sociales (Griswold, 80), la recepción de las canciones a veces no se puede prever. En los años 80 la creación o difusión de videos y la popularidad de los conciertos se convirtieron en fenómenos sociales de la industria musical que ayudaron a crear un ambiente propicio para la recepción musical en masa y a solidificar la figura de los solistas (López Rodríguez, 299). Pero como Simon Frith lo afirma, el hacer música es "una expresión y celebración de sociabilidad" (citado en Grossberg, 177). Porque incluso los solistas necesitan de una banda, de un grupo que pueda accionar en conjunto, ya sea para realizar la grabación de un álbum o la presentación de una canción.

Si consideramos los métodos comparativos literarios, en el pasado la búsqueda de influencias en los diferentes autores fue casi una obsesión. Después se pasó al concepto de intertextualidad para usarlo como eje clave en las comparaciones. Sin embargo, cuando estamos comparando siempre queda la pregunta latente: quién pudo haber influenciado o inspirado a quién? En el caso de Charly García, este argentino representó, como Bernal Villegas lo dice, una gran influencia para los músicos de rock en Centroamérica. ¿Habrá Tracy Chapman inspirado o influenciado a músicos latinoamericanos? Posiblemente, aunque eso dependería del músico, su edad, su ideología. Pero lo cierto es que Chapman vino a Costa Rica en 1988. Se presentó en el famoso concierto Derechos Humanos Ya auspiciado por la Amnistía Internacional para celebrar el Cuadragésimo Aniversario de la Declaración de los Derechos Humanos. Este concierto o gira mundial inició el 2 de septiembre de 1988 en Londres y terminó el 15 de octubre en Buenos Aires, donde precisamente 
Charly García compartió escenario con Tracy Chapman y muchos otros músicos, entre ellos Bruce Springsteen quien dijo, antes de cantar la última canción de este célebre concierto; “...la música me llenó de sueños, de vida, de potencial humano... pero sobretodo de libertad". Así, más que influencias, yo diría que tenemos paralelismos en las perspectivas y percepciones de los músicos de las Américas, abocados a través de la expresión musical para hacer consciencia y buscar bienestar social.

$\mathrm{Y}$ así, hemos hecho un breve recorrido musical por las tres Américas, comparando y contrastando el tema de libertad. Diferencias existen en el enfoque de la temática, en el tipo de imágenes o en el tono de estas tres canciones, pero incluso en sus disimilitudes, los tres textos convergen: García presenta la libertad como parte de la interioridad del individuo y concluye diciendo, "Hoy desperté cantando esa canción [de libertad] que ya fue escrita hace tiempo atrás. Es necesario cantar de nuevo, una vez más" (1923). Villegas y Loinaz la definen como una necesidad, diciendo al final, "y gritemos bien alto, queremos la paz, queremos desarmes, y la libertad" (22-25). Y Chapman se une al grupo, y junto a ellos, cantando demanda: "Freedom for everyone and freedom now" (40-41).

\section{Fuentes bibliográficas}

Bernheimer, Charles. ed. 1995. Comparative Literature in the Age of Multiculturalism. Baltimore: The Johns Hopkins University Press.

Bianciotto, Jordi. 2009. Guía Universal del Rock: de 1970 a 1990. Barcelona: Ediciones Robinbook.

Charly García. 2015. Wikipedia, La enciclopedia libre. Consulta: 20/12/3013 desde https://es.wikipedia. org $/$ w/index.php?title $=$ Charly Garc\%C3\%ADa\&oldid=83993976.

Culler, Jonathan. 2007. The Literary in Theory. Standford: Standford University Press.

Damrosch, David, Natalie Melas y Mbongiseni Buthelezi, eds. 2009. The Princeton Sourcebook in Comparative Literature. New Jersey: Princeton University Press.

García, C. "Inconsciente colectivo". 1982. Yendo de la cama al living. [CD] Argentina: SG Discos.

Griswold, Wendy. 2013. Cultures and Societies in a Changing World. Los Angeles: Sage Publications, Inc.

Grossberg, Lawrence, Cary Nelson, y Paula Treicher, eds. 1992. Cultural Studies. New York: Routledge.

López Rodríguez, Javier María. 2011. Breve historia de la música. Madrid: Ediciones Nowtilus, S.L.

Saussy, Haun. Ed. 2006. Comparative Literature in an Age of Globalization. Baltimore: The Johns Hopkins University Press.

Shénuk. 2015. Lastfm. Consulta: 18/1/2014.

Strinati, Dominic. 1995. An Introduction to Theories of Popular Culture. New York: Routledge.

Tracy Chapman. 2015. In Wikipedia, The Free Encyclopedia. Retrieved: 4/1/2014, from https://en.wikipedia. org / w/index.php? title=Tracy Chapman\&oldid $=672129155$.

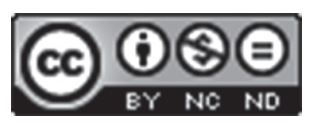

Este obra está bajo una licencia de Creative Commons Reconocimiento-NoComercial-SinObraDerivada 4.0 Internacional. 
